\title{
MORPHOLOGICAL MODELING OF A HIGHLY DYNAMIC TIDAL INLET AT SHIPPAGAN GULLY, CANADA
}

\begin{abstract}
Seth J. Logan ${ }^{1}$, Ioan Nistor ${ }^{2}$, Andrew Cornett ${ }^{3}$, Thierry Faure ${ }^{4}$ and Alain Drouin ${ }^{5}$
This paper is presenting the results of an extensive field and numerical modeling investigation of a morphologically dynamic tidal inlet. Shippagan Gully is a tidal inlet located near Shippagan, New-Brunswick, Canada, on the Gulf of Saint Lawrence. It is a particularly complex tidal inlet due to the fact that its tidal lagoon transects the Acadian peninsula and is open to the Bay des Chaleurs at its opposite end. As such, two open boundaries with phase lagged tidal cycles drive flow through the inlet, alternating direction with each tide and reaching velocities in excess of 2 $\mathrm{m} / \mathrm{s}$. Hydrodynamic and morphological processes at the site are further complicated by the presence of a highly variable wave climate. Presently, shipping practices through the inlet are limited due to continual sedimentation within and immediately offshore from Shippagan Gully. As such, an extensive field study, desktop analysis and numerical and morphological modeling of Shippagan Gully have been conducted in order to provide guidance for future works. Modeling was conducted using the CMS-Wave and CMS-Flow numerical modeling system. Sedimentation inside the inlet was shown to be ebb tide-induced deposition; while wave induced deposition was demonstrated elsewhere. The methodology and selected results of this study are presented herein.
\end{abstract}

Keywords: tidal inlets; sediment transport; morphological modeling; coastal structures

\section{INTRODUCTION}

Shippagan Gully is a coastal inlet located on the Gulf of St. Lawrence near Shippagan, New Brunswick, Canada (Figure 1). The inlet marks the south-eastern limit of a natural waterway which transects the Acadian Peninsula, providing an alternate route between the numerous commercial harbours located within the Baie des Chaleurs, and the open waters of the Gulf of St. Lawrence. The inlet, which is shown in Figure 2, has been maintained using man-made coastal structures since the late 1800 's, as its navigability has proven crucial to the local economy which is governed in large part by the fishing industry. Since the initial construction of two 300 metre jetties in 1882, a number of alterations and rehabilitations have been undertaken in an attempt to stabilize the entrance to the inlet. As a result, natural sediment bypassing along the Gulf of St. Lawrence coastline was inadvertently interrupted, an impact characterized by a shoreline retreat of over 200 metres immediately to the west of Shippagan Gully. Furthermore, sediment accumulation within the inlet became increasingly apparent, particularly on the east side of the channel, where navigable depths were steadily declining. In addition to the accumulation of sediment within the channel, the ability to navigate through the inlet was continually threatened by the presence and growth of a large crescentric ebb shoal located offshore.

${ }^{1}$ Graduate Student, Civil Engineering, University of Ottawa, 161 Louis Pasteur St. CBY A115, Ottawa, Ontario, K1N 6N5, Canada

2 Associate Professor, Civil Engineering, University of Ottawa, 161 Louis Pasteur St. CBY A115, Ottawa, Ontario, K1N 6N5, Canada

${ }^{3}$ Group Leader, Coasts, Rivers, Ports \& Oceans, Canadian Hydraulics Center, Building M-32, Montreal Rd, Ottawa, Ontario, K1A 0R6, Canada

${ }^{4}$ Scientist, Coasts, Rivers, Ports \& Oceans, Canadian Hydraulics Center, Building M-32, Montreal Rd, Ottawa Ontario, K1A 0R6, Canada

${ }^{5}$ Engineer, Public Works \& Government Services, 901 Cap-Diamant St, Quebec City, Quebec, G1K 4K1, Canada 

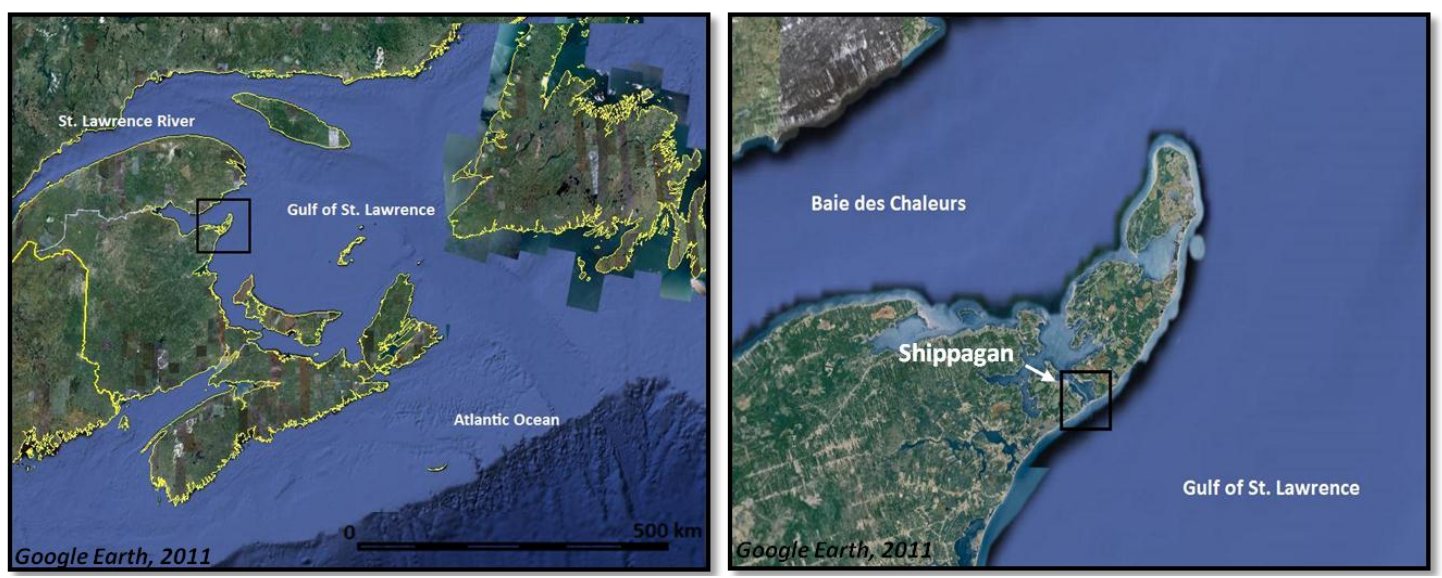

Figure 1. Satellite images showing the location of Shippagan Gully within Atlantic Canada (left) and the Acadian Peninsula (right) (Google Earth, 2011).

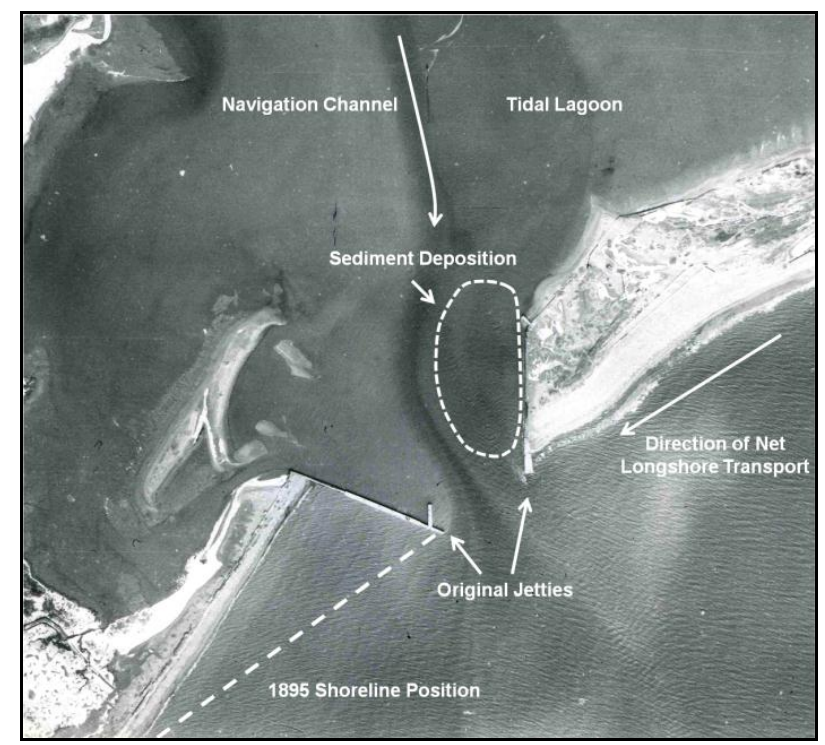

Figure 2. Earliest available aerial photograph of Shippagan Gully, taken in 1944, showing original coastal structures, beach erosion and sediment deposition within the inlet (PWGSC, 1944, with permission from Public Works and Government Services Canada).

In an effort to minimize sediment intrusion into Shippagan Gully and improve navigability of the channel, several jetty extensions were constructed throughout the late 1800's and early 20th century. These extensions however, had little lasting effect on the inlet morphology as sediment continued to amass within the confines of the inlet, particularly on the east side of the navigation channel. It was documented by engineers at the time that the sediment was arriving at the inlet from the east as longshore transport (littoral drift), which was passing around the east jetty and being deposited within Shippagan Gully. The location of deposition served to force the flow through the inlet further to the west, subsequently resulting in a curved flow path as currents exit and enter the tidal lagoon. By the early 1900's coastal erosion downdrift of the engineered inlet had become so severe that it threatened to break through the natural dune system and into the tidal lagoon to the west of the inlet. This erosion can be seen in Figure 2, characterized by a substantial shoreline retreat from its 1895 position. In response, timber breastwork was installed along the length of the west beach in order to halt the erosion, a practice which is continued to this day by means of a massive rubble mound revetment.

By the mid 20th century, mechanical dredging had become common practice at Shippagan Gully as navigational depths were continually being reduced by the significant accumulation of sediment both within the inlet and offshore along the ebb shoal. In the late 1960's and early 1970's a two part plan was put into motion in which new coastal structures were constructed at Shippagan Gully (Figure 3). 
First, a new jetty was constructed on the east side of the inlet near the mouth. This new structure was built on the inlet side of the older east jetty; however its angle differed such that it was nearly parallel to the shoreline. The new jetty stretched 90 metres to the south west, across the inlet, effectively reducing the width of the inlet mouth. It is presumed (although not documented) that the goal of the new jetty was to further constrict flow, thus increasing currents and promoting self scour at the channel entrance. The new jetty also provided increased shelter to the east side of the inlet from large currents and wave action.

The second stage of coastal works completed in the late 1960's and early 1970's involved the construction of a $600 \mathrm{~m}$ long curved vertical sheet pile training wall within the inlet. This structure was constructed off the inner tip of the west jetty, following the natural curvature of the navigation channel and progressing from the channel mouth into the tidal lagoon. It is presumed that this structure was designed to serve two purposes; one being to create a sheltered harbour in its lee, and the other being to stabilize the position of the navigation channel and promote natural scouring of the inlet. All coastal works undertaken during the 1960's and 1970's are illustrated in Figure 3.

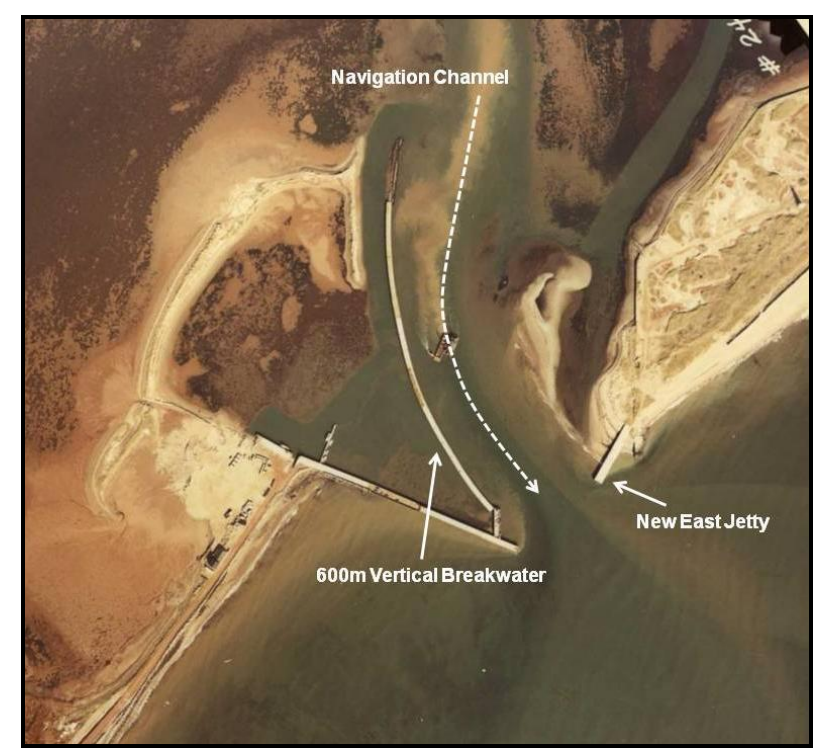

Figure 3. Aerial photograph taken in 1980 showing coastal works constructed during the late 1960's and early 1970's (PWGSC, 1980, with permission from Public Works and Government Services Canada).

Since the mid 1970's, no new coastal structures have been constructed at Shippagan Gully, nor have the existing structures been significantly modified. Furthermore, no dredging activities have been documented in the navigation channel since 1983 (the sheltered harbour, known locally as Le Goulet, was dredged in 1989). As such, the structures at Shippagan Gully have been degrading for several decades. Most notably, between 1997 and 2004, the newer east jetty was undermined resulting in a complete failure of the outer 40 metres of the structure.

In recent years, the absence of human intervention has resulted in natural morphological processes taking hold of Shippagan Gully. Sediment has continued to accumulate in the eastern part of the inlet, forcing the navigation channel to narrow and migrate westward against the curved sheet pile training wall. Many of the larger vessels which once relied on the inlet for safe and sheltered passage to and from the Gulf of St. Lawrence can no longer safely navigate the constricted channel. These vessels must now circumnavigate the Acadian Peninsula, thus considerably lengthening their journey and forcing passage through the rough waters off Miscou Point.

In 2010, the Canadian Hydraulics Center of the National Research Council (NRC) was retained by Public Works Canada to investigate the hydrodynamic and sedimentary processes at Shippagan Gully. The goal of the study was to identify the principal coastal processes responsible for the complex inlet morphology and to provide guidance for future coastal works. To accomplish these tasks, the spectral wave model CMS-Wave (USACE) was coupled with the hydrodynamic and sediment transport model CMS-Flow (USACE). These models were selected for use in this study because they embody the latest scientific knowledge and numerical techniques, and have been developed for and applied primarily to 
simulate coastal processes at tidal inlets. Furthermore, complex interactions between currents, waves and sediments, such as those present at Shippagan Gully are addressed by coupling the two models.

\section{FIELD INVESTIGATIONS AND PRELIMINARY ANALYSES}

A site visit to Shippagan Gully was completed in August 2010 during which field work was performed and historical information gathered from local sources. Current velocity measurements were taken in the inlet during both ebb and flood spring tides using an electromagnetic current metre while measurement positions were mapped using GPS (Global Positioning System). Sediment samples were extracted at various locations both updrift and downdrift from Shippagan Gully, as well as from within the inlet. Sediment samples were subsequently analyzed in a laboratory setting in order to obtain sediment properties for input into the coupled numerical models. Current velocity measurements were later used for calibration and validation of the hydrodynamic numerical model.

A detailed site history was developed for Shippagan Gully from local knowledge and available data, including documentation of past coastal works and a complete dredging record (1882 to present time). Historical aerial photographs were provided courtesy of Public Works Canada and georeferenced in order to provide a means for quantitative comparison of historical shoreline positions and sediment deposition patterns. From this information, morphologic trends at Shippagan Gully were deduced, providing a basis of understanding for the unique features present at the site. Historical shoreline positions were digitized from the georeferenced aerial photographs, from which sediment erosion and deposition rates were estimated. From this analysis it was determined that approximately $2100 \mathrm{~m}^{3}$ of sediment is deposited annually within the confines of Shippagan Gully (not including the ebb shoal complex), providing a quantitative estimate from which to calibrate the numerical model. A selection of digitized shoreline positions (1980 to 2008) is presented in Figure 4.

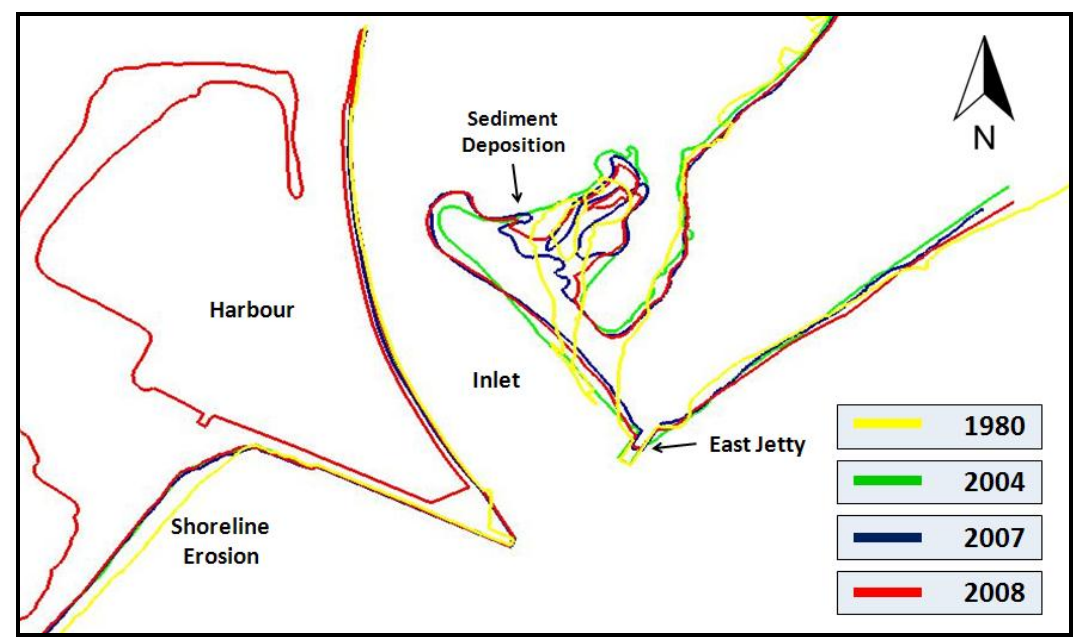

Figure 4. Shoreline locations digitized from historical aerial photographs, showing the progressive accumulation of sediment and unique morphologic formations within Shippagan Gully.

Bathymetry for Shippagan Gully and the surrounding area was provided courtesy of Public Works Canada. Offshore bathymetry was interpolated from nautical charts, while nearshore, channel and tidal lagoon bathymetry were obtained from bathymetric survey data. Navigation channel bathymetry within the tidal lagoon and inlet were available periodically from 1992 to 2010, while nearshore and tidal lagoon bathymetric surveys were only available for 2010. As such, significant engineering judgement, interpolation, and smoothing were required for the creation of bathymetric datasets corresponding to all years prior to 2010 .

Historical wave data over the Gulf of St. Lawrence was obtained from the MSC50 Atlantic Wave Hindcast developed by Environment Canada (Swail et al., 2006). The MSC50 Hindcast provides hourly estimates of wave height, period and direction across the entire Gulf of St. Lawrence at 0.1 degree grid spacing. The hindcast, which is based on NCEP/NCAR 10-metre wind fields and covers the 54 year period from 1954 to 2008, has previously been calibrated and validated against available buoy data. Further validation was performed by the present author prior to using the wave data.

An offshore wave climate was developed for Shippagan Gully from MSC50 Hindcast data extracted from a grid point $5 \mathrm{~km}$ offshore from the inlet, and at a depth of approximately 16 metres. 
Wave roses and frequency tables were compiled from the wave data and a detailed statistical analysis of the full data set was performed. Storm events were separated from the analysis using the peak over threshold method and an extreme value analysis of the separated data was completed. From the wave roses, 5 principal directions of propagation $\left(30^{\circ}\right.$ directional bins) were identified, covering a range from $240^{\circ}$ to $360^{\circ}$ true north. Daily wave conditions and return period events were subsequently determined within each directional bin, forming a statistical basis for wave input to the spectral wave model. Offshore wave heights at Shippagan Gully were found to rarely exceed 3.0 metres with periods of generally less than 12 seconds. Direction of wave propagation was found to be highly variable between the 5 principal directional bins, with strong components from both the East and the South, resulting in bi-directional longshore transport. This directional variability in wave energy is shown in Figure 5 in the form of wave height and wave period roses, where the direction is shown as the direction to which the waves are propagating.
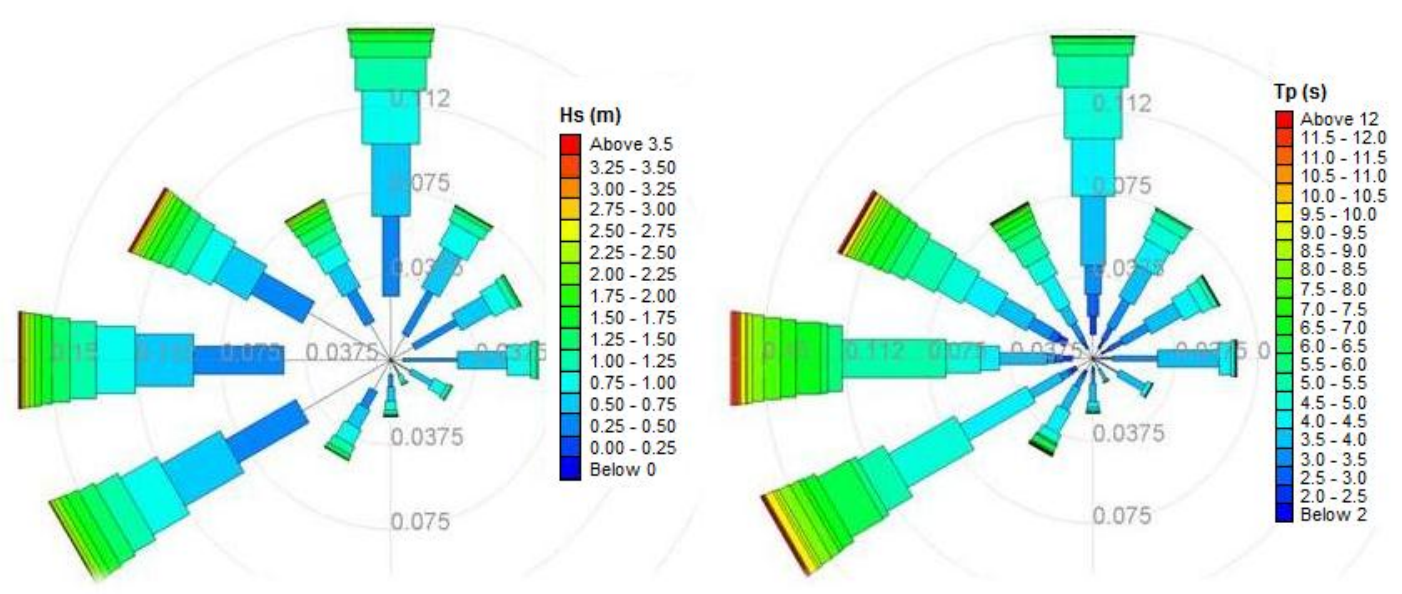

Figure 5. Significant wave height (left) and peak spectral period (right) roses, which illustrate the directional spread of wave energy at a location $5 \mathrm{~km}$ offshore from Shippagan Gully.

Measured water level data was sparsely available near Shippagan Gully. A tidal prediction model for the Gulf of St. Lawrence is however maintained by Canadian Hydrographic Services (CHS), with tidal constituents available at a $5 \mathrm{~km}$ grid spacing throughout the entire St. Lawrence estuary. As such, coefficients for 30 tidal constituents were obtained for three locations surrounding Shippagan Gully. A regional finite-element model of tidal hydrodynamics around the Acadian Peninsula was developed for this study, based on the TELEMAC modeling system. Boundary conditions for the regional tidal model were created from the tidal constituent data obtained from CHS. The regional tidal model was used to develop appropriate tidal boundary conditions for the high-resolution modeling of Shippagan Gully, conducted using CMS-Flow and CMS-Wave. An inland water level boundary was placed at the northwestern limit of the high resolution model domain, as water levels at this location (within the tidal lagoon) differ greatly from those along the Gulf coast. This is due to the tidal phase lag that exists between the Baie des Chaleurs and the Gulf of St. Lawrence. It is this phase lag that drives flow through Shippagan Gully, creating very strong ebb flows (exceeding $2 \mathrm{~m} / \mathrm{s}$ ) while the flood flows are comparatively weak (generally less than $1 \mathrm{~m} / \mathrm{s}$ ).

Two offshore water level boundaries were used to represent tides in the Gulf of St. Lawrence for the hydrodynamic model (CMS Flow). Two offshore boundaries were implemented due to the fact that a strong counter-clockwise hydrodynamic circulation is present in the Gulf of St. Lawrence, creating longshore currents from north to south along the New Brunswick coastline. This phenomenon is reproduced in the hydrodynamic model by implementing two offshore boundaries, one at each longshore limit of the model domain. These two offshore boundaries have slightly phase-lagged tidal cycles (extracted from the regional TELEMAC model), thus driving flow in the longshore direction. CHS tidal prediction locations, CMS-Flow model domain and CMS-Flow water level boundary locations are illustrated in Figure 6. 


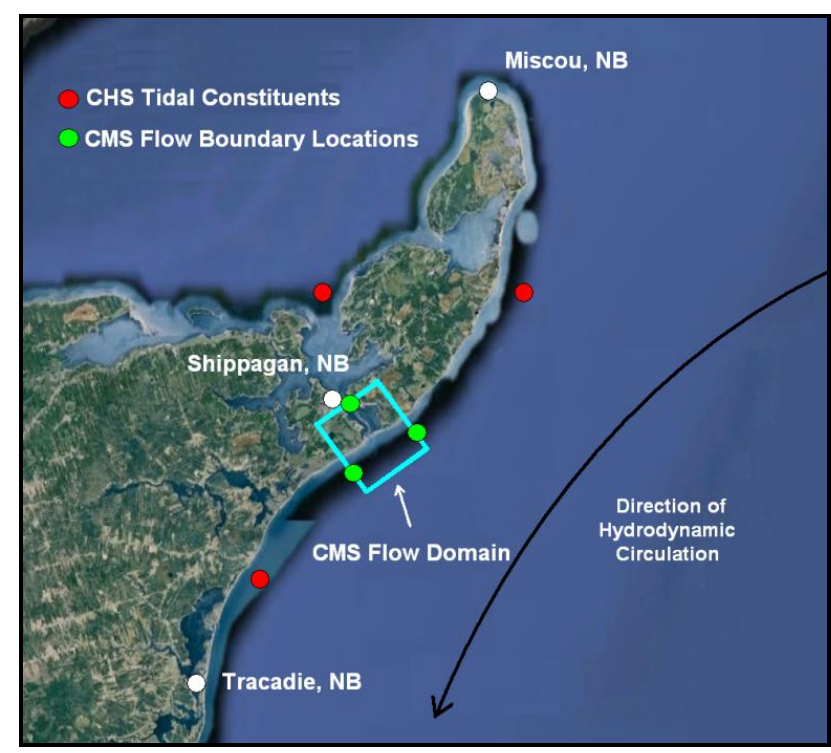

Figure 6. A regional tidal model was developed and applied to predict the tidal fluctuations at three locations corresponding to the boundaries of the CMS-Flow domain (pictured). Model input was based on tidal constituent data obtained from CHS (Google Earth, 2011).

\section{NUMERICAL MODEL SET-UP AND CALIBRATION}

The numerical models CMS-Flow and CMS-Wave were used in the present study to simulate inlet hydrodynamics, sediment transport and morphology change at Shippagan Gully. Both models are developed by the United States Army Corps of Engineers (USACE) under the Coastal Inlets Research Program (CIRP) and are therefore designed for the primary purpose of modeling coastal inlets. CMSFlow is a two dimensional, hydrodynamic and sediment transport model, capable of simulating morphology change over relatively long time scales (Buttolph et al. 2006). CMS-Wave is a two dimensional spectral wave model which calculates wave propagation and transformation through the nearshore zone, including wave breaking and radiation stresses (Lin et al. 2008). Both models operate on a finite difference grid with variable grid spacing, such that areas of interest can be modeled at a higher resolution without greatly sacrificing computation time. For this study, the grid spacing for both the hydrodynamic model and the wave model was 80 metres at the offshore boundary, reducing to 10 metres within Shippagan Gully.

For the present study the hydrodynamic and wave models were coupled together through the use of a steering module, which permits the models to share calculated information at a user specified interval. By coupling the two models in this manner, wave propagation and transformation calculations account for variable water levels and updated bed morphology while wave induced currents are included in sediment transport calculations (Militello et al. 2003). This method of coupling models is ideal for modeling a highly dynamic coastal inlet such as Shippagan Gully, where complex interactions between tide induced currents and nearshore waves are likely to influence local sediment transport patterns.

Calibration of the coupled numerical model was split into two separate tasks. First, a hydrodynamic calibration was completed based on current velocities measured during the August 2010 field investigation. Predicted water level fluctuations for the three day period in which the field study was conducted were used as input to the numerical model, with no influence from waves. Observed tidal lagoon flow paths were forced by introducing large bed friction coefficients throughout the shallow, vegetated areas within the lagoon. Friction coefficients within the observed flow paths and nearshore region were adjusted until an acceptable agreement was reached between modeled and measured current velocities within Shippagan Gully, during both the strong ebb and weak flood tidal flows. Finally, a local friction coefficient was adjusted independently at the inland limit of the tidal lagoon, as it was determined that the local friction at this boundary governed the timing of flow through the inlet. The tidal hydrodynamics were considered to be well calibrated when the mean residual error between the measured and predicted velocities was reduced to just $0.04 \mathrm{~m} / \mathrm{s}$. This error was accepted based on the fact that it represents a mean deviation of only $2 \%$ in maximum recorded velocities, which are approximately $2 \mathrm{~m} / \mathrm{s}$ and occur during the ebb tide. 
Following the successful hydrodynamic calibration, morphologic calibration was performed in order to ensure that the model was capable of reproducing the historical morphologic evolution observed at Shippagan Gully. A calibration period of 1992 - 1998 was chosen due to the fact that reasonable measured bathymetry was available at both the beginning and end of the time period. Furthermore, no major human interventions took place during the 6 year time span, thus meaning that observed morphological change occurring during this time period was natural.

A variable grain size bed was implemented in the numerical model, to account for natural armoring that was hypothesized to exist in regions of high flow velocity such as at the inlet mouth. The local value for bed grain size influences the calculation of critical shear stress and subsequently the hydrodynamic requirements for incipient sediment motion. This spatially variable dataset was adjusted until the numerical model was able to reproduce the historical erosion and deposition patterns observed over two years. Once this spatial calibration was deemed satisfactory, the global transport grain size was adjusted in order to alter the rate at which the morphological changes progressed. Historical surveyed cross-sections of the navigation channel from 1992 to 2010 were used during this process. The goal of this temporal calibration was to match the navigation channel's rate of westerly migration. The spatial and temporal approaches to morphologic calibration were performed iteratively, until an acceptable reproduction of both deposition patterns and deposition rates was reached, based on the available historical data.

\section{NUMERICAL MODEL RESULTS}

\section{Governing Morphological Processes}

Once the numerical model had been successfully calibrated with respect to both hydrodynamics and morphological trends, the calibrated model was used as an analytical tool to help identify governing coastal processes responsible for sediment deposition at Shippagan Gully. With this in mind, the following questions were investigated:

- Where is sediment being deposited,

- When is sediment being deposited,

- Why is deposition occurring, and

- Where is the sediment coming from.

To address these questions the calibrated numerical model was re-run for the 6 year period from 1992 to 1998 inclusive. Time series of predicted morphological change at specific points of interest in the numerical model domain were extracted and analyzed. Three grid points of specific interest are picture in Figure 7, overlaid on 1992 bathymetric contours representative of the numerical model bathymetry at the start of the 6 year simulation.

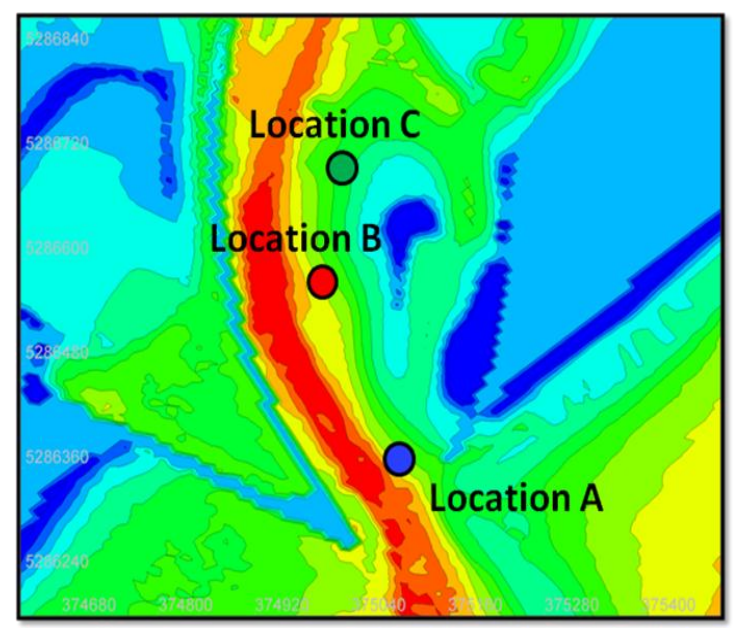

Figure 7. Three locations at which time series of predicted morphology were extracted for further analysis, overlaid on 1992 bathymetry; the starting bathymetry for the numerical model simulation.

A time series of bed elevations was plotted for each of the three locations depicted in Figure 7. From these plots, morphological trends at each of the three locations can be deciphered as they pertain to other time varying parameters such as tides and waves. Time series of modeled depths (below 
MWL) for each of the three locations are presented in Figure 8, accompanied by a time series of water surface elevations for the entire 6 year simulation. It should be noted that a morphological acceleration factor of 16 was used in this simulation. As such, hydrodynamics were simulated for a total of 137 days, which results in 2192 days of morphological time, or 6 years.

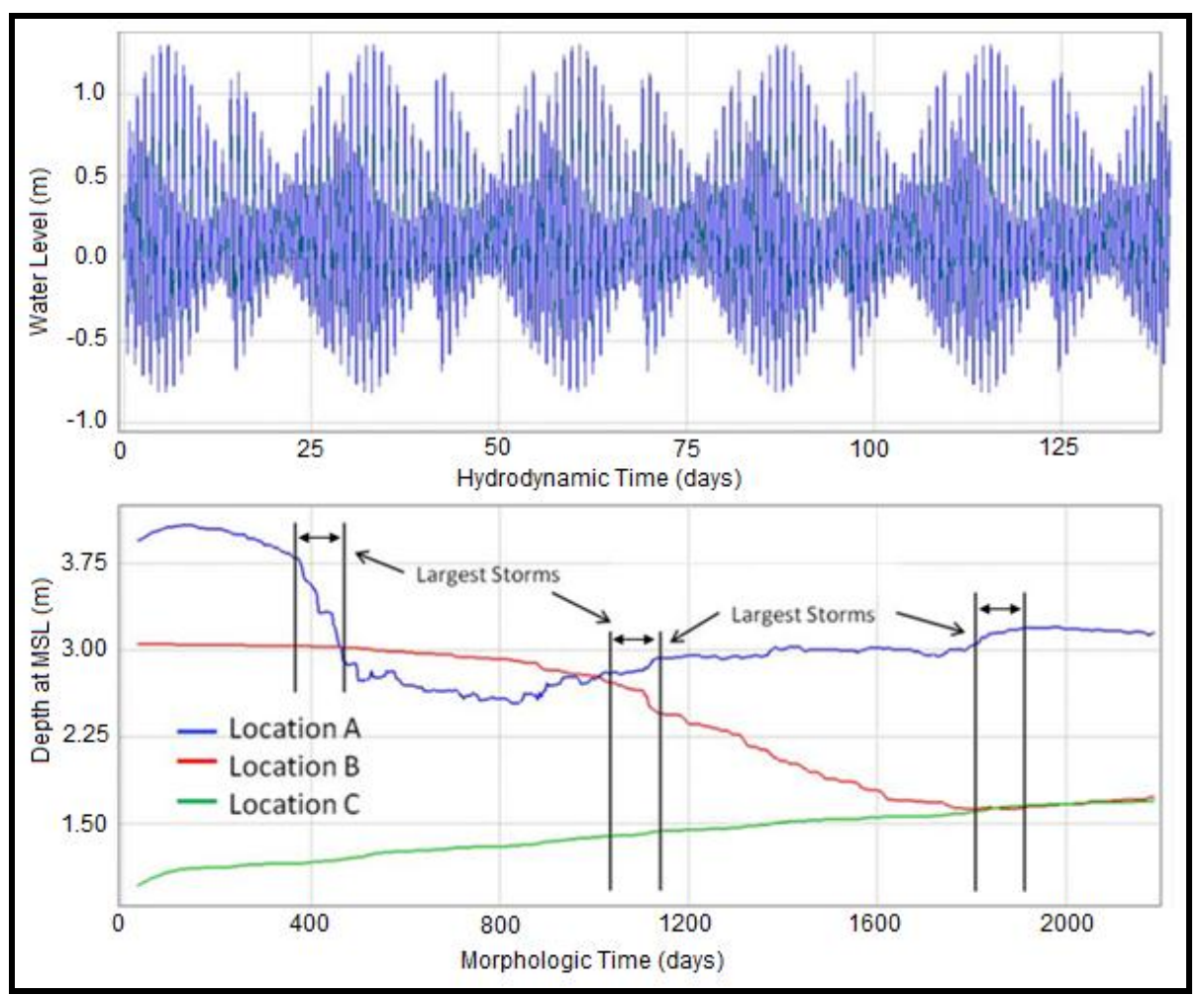

Figure 8. Time series of water levels at numerical model boundaries and available depth (at MSL) at the three locations defined in Figure 7 above, for a 6 year morphological simulation starting from the 1992 bathymetry.

From Figure 8 several important observations can be made. First, from looking at the temporal morphology change at location A, it is apparent that both deposition and erosion occur at this location, and are highly variable with no apparent long term trend. Furthermore, significant changes in depth (below MWL) are observed at location A during periods of intense wave action, such as during the stormy periods highlighted in Figure 8. These observations indicate that at this location at the inlet mouth, sediment deposition is wave-dominated. Conversely, locations B and C depict relatively smooth long term trends and are not subject to the variability demonstrated at location A. Furthermore, location $\mathrm{B}$ and $\mathrm{C}$ do not seem to be overly influenced by periods of intense wave action. Hence, the numerical model results indicate that morphology changes which occur at locations $\mathrm{B}$ and $\mathrm{C}$ are tidedominated.

By inspecting the same bed elevation time series at a higher temporal resolution, another important observation is made. It can be seen from Figure 9 that at location B (similar for location C), morphology change occurs primarily during the ebb-flows, while little to no change is observed during the flood-flow. As such, not only does the numerical model show that deposition/erosion zones B and $\mathrm{C}$ are tide-dominated, but it indicates more specifically that they are $e b b$-tide dominated. 


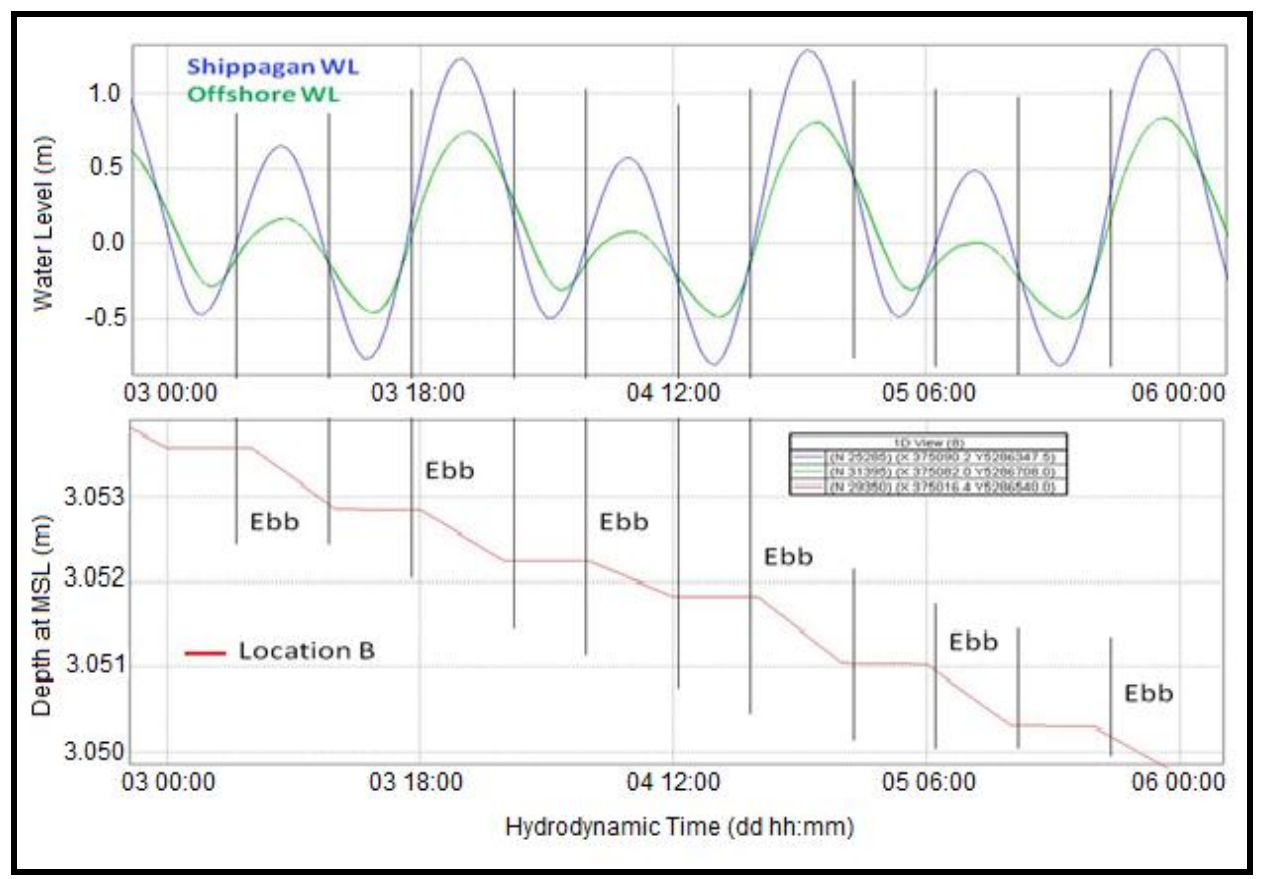

Figure 9. High temporal resolution plot of available depth (at MSL) at location B as it compares to the timevarying water levels at the numerical model boundaries.

Once the governing processes for morphological change were identified within Shippagan Gully, a justification for this deposition was sought. Wave-induced deposition occurring at the inlet mouth is easily explained by the previously discussed presence of a net longshore transport of coastal sediment from northeast to southwest. Sediment arrives at Shippagan Gully from the northeast and is subsequently deposited in the sheltered confines of the ebb-shoal near the inlet mouth or is transported offshore and along the ebb-shoal by the combined effects of easterly waves and the strong ebb-current.

Tide-dominated deposition within the inlet on the east side of the navigation channel is however slightly more difficult to explain. The likely reason for this sediment deposition and subsequent migration of the navigation channel is the fact that water passing through Shippagan Gully must flow around a large bend, guided by the curved sheet-pile training wall. As such, the highest current velocities are found on the outside of the bend (near the sheet-pile wall), while comparatively lower velocities are present on the inside of the bend. This phenomenon results in erosion of the outer bank, while sediment deposition is promoted along the inner bank. This process is analogous with the behaviour of a meandering river. Small river bends tend to expand radially outwards, eroding the outer bank and creating shallow sloping deposition banks (bars) on the inside of the bends. This eventually culminates in the formation of an oxbow and typically progresses at a faster rate when the flow is higher (in this case during the ebb-flow). Figure 10 illustrate this phenomenon and its manifestation at Shippagan Gully. 


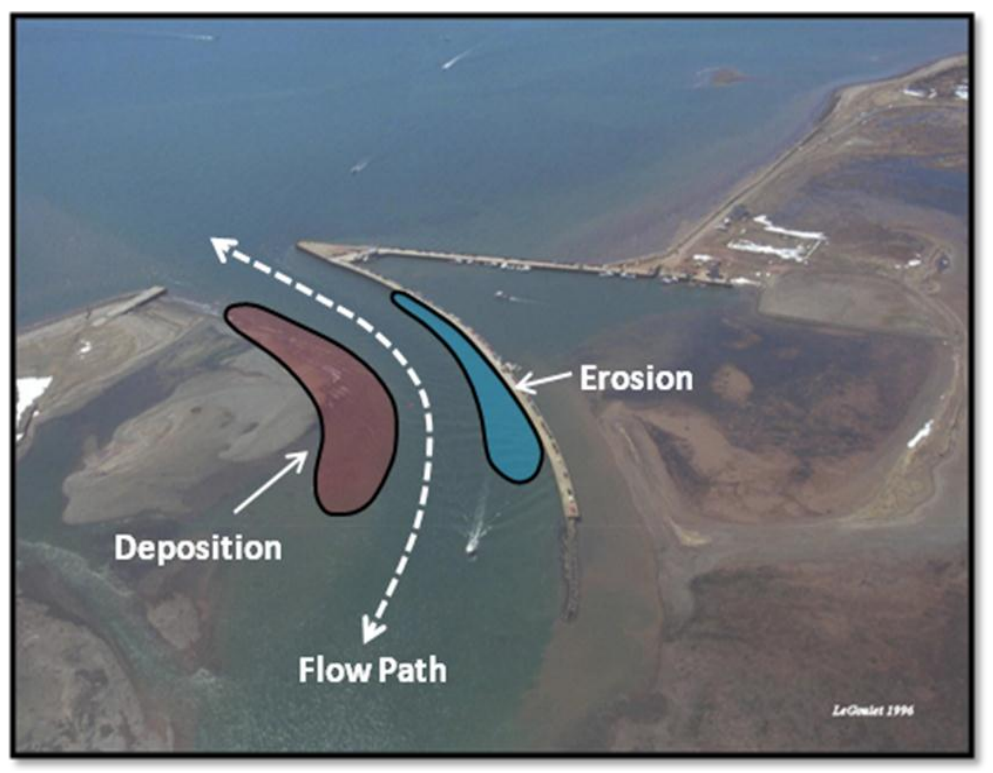

Figure 10. Aerial photograph of Shippagan Gully taken in 1996 showing the curved flow path followed by the strong ebb-current as it exits the inlet (PWGSC, 1996, with permission from Public Works and Government Services Canada).

Although the mechanisms responsible for both the deposition at the inlet mouth and along the eastern bank of the navigation channel (resulting in the westerly migration of the channel) are successfully modeled and identified, the 6 year morphological simulations $(1992-1998)$ were unable to reproduce any of the deposition on the eastern side of the inlet which is so apparent above MSL in the aerial photographs. As was previously discussed, an estimated $2100 \mathrm{~m}^{3}$ of sediment is deposited in this region above the $-1 \mathrm{~m}$ (GD) contour each year. Furthermore, deposition in this area reaches elevations of over $2 \mathrm{~m}$ above LWL. As such, it is likely that a hydrodynamic process occurring above the typical tidal range is responsible for this substantial amount of deposition. The effects of elevated water levels due to storm surge were therefore investigated using the numerical model.

Unfortunately, no measured storm surge data are available for the Gulf Coast surrounding Shippagan Gully. As such, an estimated water surface elevation adjustment of $1 \mathrm{~m}$ was used based on anecdotal information from locals and high water marks observed in the field. A 12 hour period encompassing the maximum spring tide was simulated with the addition of this $1 \mathrm{~m}$ to the water surface elevation at all three model boundaries and for a variety of storm conditions. The 2010 bathymetry was used as the starting bathymetry for the storm surge simulations. Wave parameters corresponding to annual storm events from $270^{\circ}, 330^{\circ}$ and $360^{\circ}$ were input to the numerical model and each 12 hour storm was simulated individually. Results from these simulations were compared to results from identical simulations performed without the additional surge, in order to determine the relative effects that this increased water level has on local morphology change during large storm events.

Numerical model results indicated that with the addition of $1 \mathrm{~m}$ of storm surge, wave energy inside the inlet is increased by up to $50 \%$ for the simulated conditions. This is largely due to the fact that less breaking occurs over the extensive ebb-shoal with the additional $1 \mathrm{~m}$ depth, thus allowing larger waves to propagate into the inlet itself. These larger waves are shown to diffract around the eastern side of the inlet entrance and break along the accreted beach which lies along the east side of the inlet.

Figure 11 presents color contour plots of morphological change for simulations without (left) and with (right) $1 \mathrm{~m}$ storm surge. These results correspond to an annual storm event approaching from the $330^{\circ}$ directional bin. Waves during this event had an offshore significant wave height of $2.65 \mathrm{~m}$ with a peak spectral period of $8.25 \mathrm{~s}$. It can be seen from this figure that within the inlet a great deal of morphological change is incurred along the beach on the eastern side of the navigation channel for the simulation which includes storm surge. This change is characterized by slight erosion at higher elevations, and significant deposition near the water line: a pattern consistent with that of a storm induced S-shaped beach profile. Conversely, for the same simulation with no additional surge, virtually no morphological change is modeled in this region. 

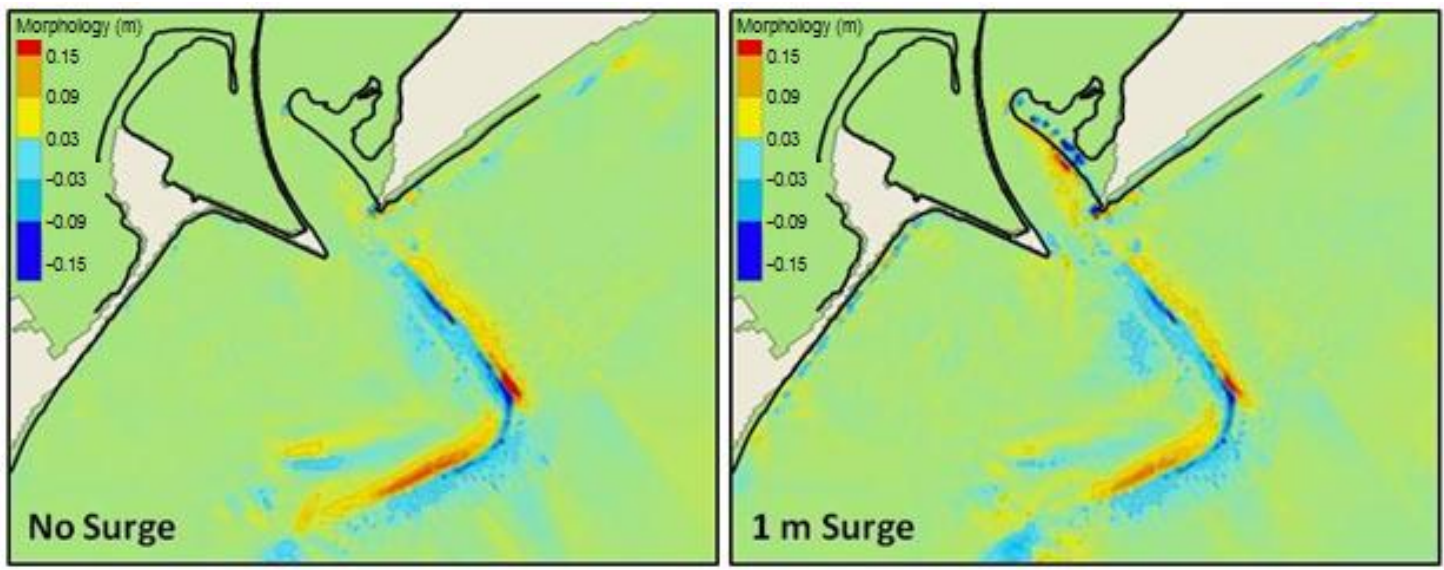

Figure 11. Morphology change after 12 hour annual storm with waves from 3300 during a maximum spring tide with no additional storm surge (left), and with $1 \mathrm{~m}$ storm surge (right).

\section{Assessment of Alternative Design Scenarios}

Based on the findings presented thus far, a number of alternative design options were formulated with the objective of improving the navigability of Shippagan Gully. The numerical model was first applied to assess what can be expected of Shippagan Gully if the status quo is maintained. Alternative structural scenarios were then modeled (each starting from the 2010 bathymetry) and the results compared to that of the status quo, in order to determine if the current situation at Shippagan Gully can be improved upon by structural means. The major areas of interest in which improvements were sought, corresponded to the three deposition zones outlined in above, which are summarized as follows:

- Wave-dominated deposition at the inlet mouth;

- Storm-wave and storm-surge dominated deposition on the east side of the inlet; and

- $\quad$ Ebb-tide dominated westerly migration of the navigation channel.

The calibrated numerical model was first successfully applied to study the possible effects of maintaining the status quo at Shippagan Gully. From these simulations it was determined that both sediment deposition and westerly migration of the navigation channel are likely to continue if no intervention is made. The model suggests that future deposition will be most significant at and immediately offshore from the inlet mouth. It also indicates that the narrowest part of the channel may be approaching a cross-sectional equilibrium state. It is important to note however that the equilibrium cross-section is not sufficient to ensure the navigability of the inlet.

Several alternative human interventions (design scenarios) have been formulated in an attempt to seek improvements to the status quo. These scenarios were created based on the developed understanding of coastal and morphological processes discussed herein. Several east jetty configurations were proposed and tested, in order to analyze the effects of placing a new jetty on the east side of the inlet mouth (refer to Figure 12a). It was determined that an east jetty can be effective in trapping or partially diverting littoral drift approaching from the northeast, subsequently reducing deposition within and immediately offshore from the inlet mouth. The numerical model indicates that a long, shore-perpendicular jetty provides the best improvements in these regards. Furthermore, a jetty which provides protection from waves in general and easterly waves in particular has been shown to be highly effective in reducing sediment deposition inside Shippagan Gully. This can be achieved by locating the jetty further to the west (reducing the width of the inlet mouth), and/or by introducing a southerly bend in the jetty plan-form. However, care must be exercised in placing a jetty, particularly a long, shore-perpendicular jetty, at a coastal inlet such as Shippagan Gully where natural sediment bypassing has been shown to occur. The introduction of a sediment trapping structure could (temporarily) interrupt the natural bypassing of sediment, subsequently reducing the sediment supply to the down shore region and potentially creating erosion. Hence, the benefits of extending the existing jetty must be balanced against the potential for increased shoreline recession to the southwest of the inlet.

In order to address the westerly migration of the navigation channel, several alternative scenarios were simulated and assessed. Armoring the west bank of the navigation channel has been shown to slow (or halt) erosion, providing a possible solution for protecting the curved breakwater from eventually being undermined. The armoured bank does not however produce a significant decrease in 
sediment deposition on the eastern bank, and subsequently does not appear to help widen or deepen the navigation channel.

Additional armoring at the centre of the curved breakwater was investigated, in order to protect the bank against erosion while simultaneously reducing the curvature of the primary flow path through the inlet. However, the reduced navigational depths due to the addition of scour protection in the channel far offset the slight improvement in deposition patterns on the east side of the channel. As such, armoring the west bank of the navigation channel has not been shown to improve the navigability nor the morphodynamic trends at Shippagan Gully.

Several inlet configurations with parallel training walls were studied in which a curved structure is constructed on the east side of the navigation channel, parallel to the existing curved breakwater (Figure 10b). The bathymetry in these scenarios was adjusted such that a minimum depth of $1.5 \mathrm{~m}$ was obtained between the parallel structures (in the channel). This was done in order to ensure flow across the entire newly defined channel. Numerical model results indicate that adding a parallel training wall is an effective means of reducing deposition within the channel. Of the two primary training wall configurations that were investigated, the configuration that creates an $80 \mathrm{~m}$ wide navigation channel performed better than the one that creates a $140 \mathrm{~m}$ wide channel (although the model indicates that both options offer an improvement over the status quo).

Another viable option that was not investigated in the present study is to institute a program of mechanical dredging to maintain a channel with sufficient depth and width for safe navigation. Historical evidence suggests that dredging was used to maintain the navigation channel at Shippagan Gully throughout much of the $20^{\text {th }}$ century. A cost benefit analysis would however have to be completed to assess this option, as both the present study and the extensive history of the site have shown that considerable and frequent mechanical dredging would have to be performed in order to maintain adequate navigable depths.
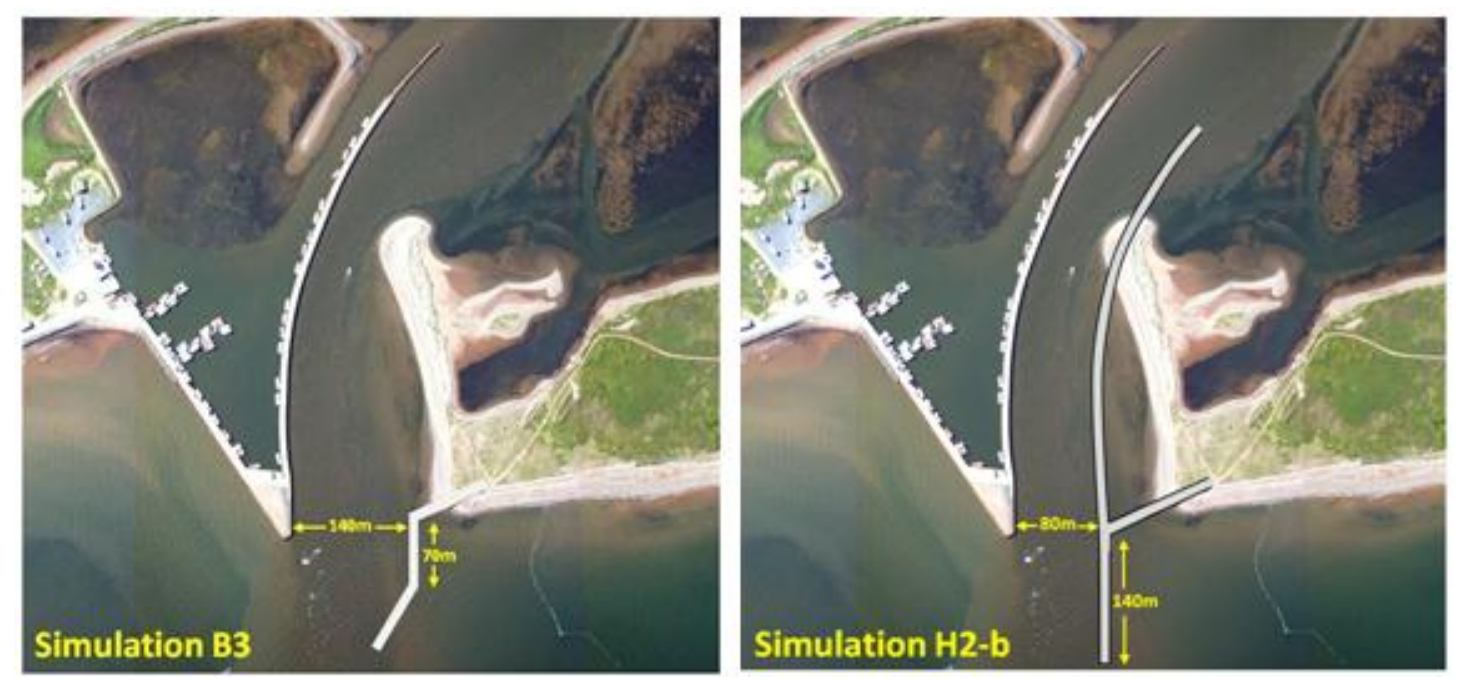

Figure 12. Examples of a new east jetty concept (left) and a parallel training wall culminating in a jetty (b) which were simulated using the calibrated numerical model.

\section{CONCLUSIONS}

The present study has been successful in identifying the governing coastal processes responsible for the complex morphology which is present at Shippagan Gully. A detailed and accurate knowledge of the local wave climate has been developed and a good understanding of the local water levels has been obtained. From this information, a coupled numerical model of the hydrodynamic and coastal processes at the inlet was developed using the numerical models CMS-Flow and CMS-Wave, via the SMS10.0 user interface. With data measured during an August 2010 field investigation campaign supplemented by an understanding of historical morphology change obtained from an analysis of georeferenced aerial photographs and dredging records, the numerical model was successfully calibrated with regards to both hydrodynamics and morphodynamic evolution. The calibrated model was therefore able to simulate the complex hydrodynamics at the site due to the combined effects of waves and tides with fairly good accuracy. However, due to the complexity of the site and the limitations of 
CMS-Flow (one of the most advanced coastal modeling tools available at the time of this study), the long-term changes in morphology could only be modeled in an approximate, qualitative manner.

Using the calibrated numerical model as an analytical tool, simulated morphodynamic trends were analyzed in order to determine where sediment was being deposited, when the deposition occurred, and the coastal processes responsible for the deposition. It was determined that three inter-related processes were primarily responsible for the decreasing navigability of Shippagan Gully. The navigation channel has been shown to migrate further and further to the west each year, ultimately becoming narrower as it approaches the curved breakwater on the west side of the inlet. The numerical model indicates that this migration is caused by the strong ebb-tide currents which follow a curved flow path as they exit Shippagan Gully. This bend in flow causes outward erosion of the west bank, while depositing sediment along the east bank of the navigation channel.

A second morphological process identified at Shippagan Gully is the deposition of sediment at, and immediately offshore from the inlet mouth. This sediment has been shown to arrive at the inlet from the northeast as longshore transport. This net longshore transport is created by the local wave climate which is dominated by energetic easterly waves. Under certain wave conditions, the longshore transport has been shown to carry sediment along the extensive crescentric ebb-shoal which exists offshore from the inlet, subsequently returning sediment to the shoreline down-drift of Shippagan Gully (to the southwest). Some of the sediment arriving at the inlet is however deposited in the shallow waters in lee of the ebb-shoal and on the east side of the inlet mouth, where ebb-flow velocities and associated scour potential are small.

The third and final morphological process identified at Shippagan Gully is the above-LWL deposition of sediment along the eastern side of the inlet, and at elevations along the berm exceeding 2 $\mathrm{m}$. The numerical model indicates that this deposition is caused by storm waves accompanied by storm surge, which allows larger, more energetic waves to propagate further into the inlet than would otherwise occur within the normal tidal range. These larger waves are capable of transporting sediment from the ebb shoal into the inlet where it is deposited to the east of the navigation channel. The main sedimentary processes identified at Shippagan Gully are summarized in Figure 13.

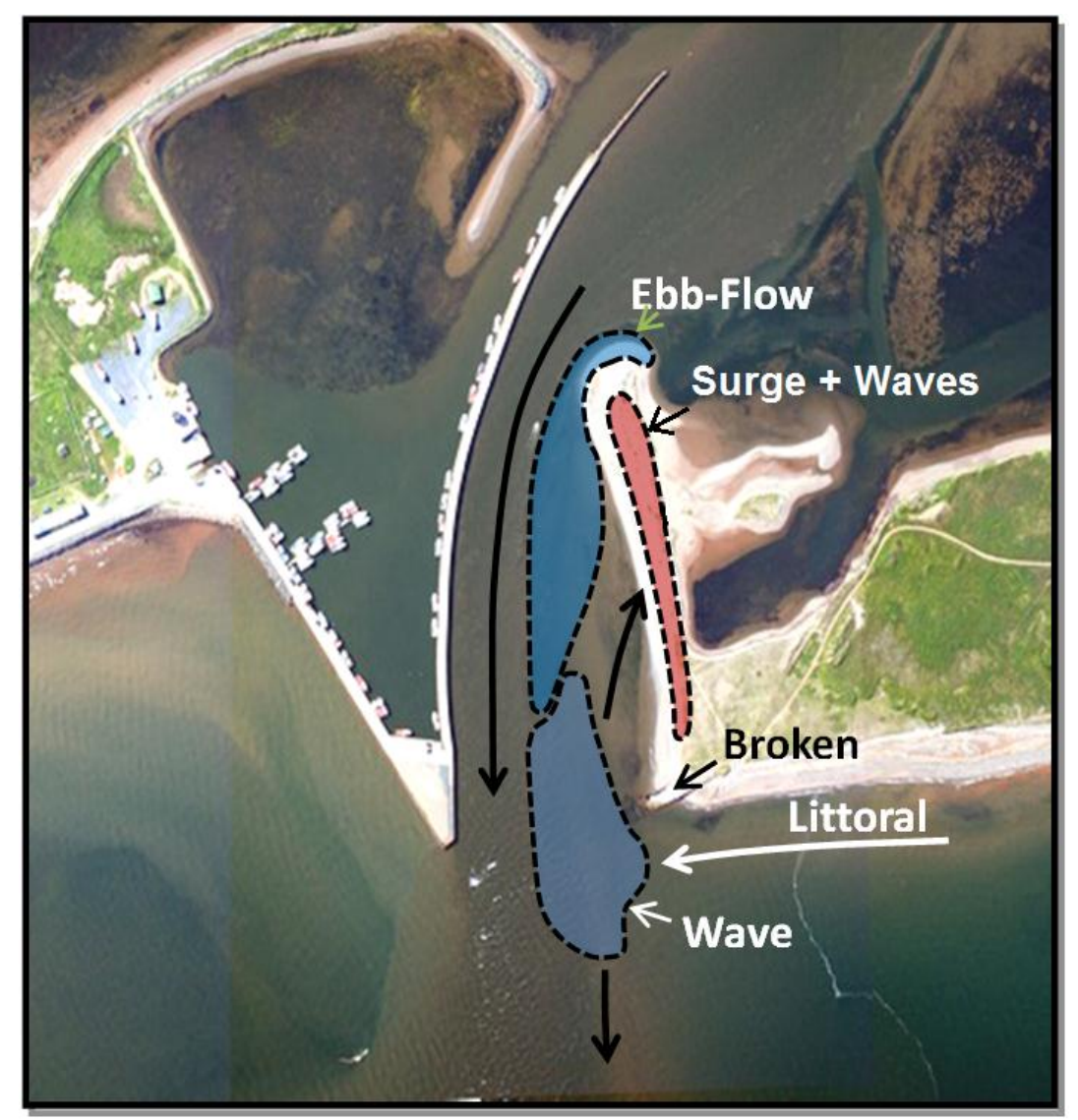

Figure 13. Summary of identified deposition zones and generating coastal processes, overlaid on a 2008 aerial photograph of Shippagan Gully. 
The calibrated numerical model was successfully applied to study the possible effects of several configurations of coastal structures and stone placement in comparison to the status quo. From these simulations it was determined that various alignments of a single jetty or of a parallel training wall culminating in a jetty on the east side of the inlet could result in a significant improvement to the navigability of the inlet while reducing the requirement for perpetual maintenance. Maintenance dredging was also shown to be a viable option although not reported herein.

The author would like to stress that Shippagan Gully is an very complicated coastal inlet, due to the asymmetry of tidal forcings, the numerous historical human interventions, the vast supply and mobility of coastal sediment, and the highly complex interaction of both hydrodynamic and morphodynamic coastal processes. Based upon the findings of this study, a much better understanding of the complexities present at Shippagan Gully has been achieved. Reasonable estimates of the changes to be expected in future for the status quo option and for a wide range of plausible human interventions have been determined. The level of confidence for these estimates however is limited by a relative lack of detailed field data and by the inherent limitations of the CMS-Flow model. In future, the level of confidence and precision of the numerical modeling could be improved significantly if it were supported with additional field data on sediment properties and spatial sediment distribution.

Despite the uncertainties, the knowledge and information generated by this study can be used by PWGSC to help make informed decisions concerning future human interventions at Shippagan Gully and their impacts.

\section{ACKNOWLEDGMENTS}

The authors of this paper would like to acknowledge Public Works and Government Services Canada for providing the funding required for this study. The support of the Natural Science and Engineering Council (NSERC) through its Discovery Grant is also acknowledged. Additional recognition is directed to Environment Canada and the Canadian Hydrographic Services for supplying historical documentation as well as pertinent site data which was crucial to the completion of this project. Finally, thanks must be given to the United States Army Corps of Engineers (ERDC-CHL) for their extensive support throughout the numerical modeling process.

\section{REFERENCES}

Buttolph, A.M., Reed, C.W., Kraus, N.C., Ono, N., Larson, M., Camenen, B., Hanson, H., Wamsley, T., Zundel, K.2006. Two-Dimensional Depth-Averaged Circulation Model CMS-M2D: Version 3.0, Report 2, Sediment Transport and Morphology Change. Coastal Inlets Research Program, USACE. ERDC/CHL TR-06-9.

Buttolph, A.M., Grosskopf, W.G., Bass, G.P., and Kraus, N.C. 2006. Natural Sand Bypassing and Response of Ebb Shoal to Jetty Rehabilitation, Ocean City Inlet, Maryland, USA. Proceedings $30^{\text {th }}$ Coastal Engineering Conference, World Scientific Press, San Diego, California, USA. 3344-3356.

Lin, L., Demirbilek, Z., Mase, H., Zheng, J., Yamada, F. 2008. CMS-Wave: A Neashore Spectral Wave Processes Model for Coastal Inlets and Navigation Projects. Coastal Inlets Research Program, USACE. ERDC/CHL TR-08-13.

Miliello, A., Zundel, A.K., 2003. SMS Steering Module for Coupling Waves and Currents, 2: M2D and STWAVE. Coastal Inlets Research Program, USACE. ERDC/CHL CHETN-IV-60.

Swail, V.R., Cardone, V.J., Ferguson, M., Gummer, D.J., Harris, E.L., Orelup, E.A., Cox, A.T. 2006. The MSC50 Wind and Wave Re-analysis. Environment Canada and Oceanweather Inc. $9^{\text {th }}$ International Workshop on Wave Hindcasting and Forecasting, Victoria, BC, Canada. 